\title{
Article \\ Thermoluminescence Analysis of the Clay Core of Bronze Statues: A Re-Appraisal of the Case Studies of Lupa Capitolina and Other Masterpieces in Rome
}

\author{
Marco Martini * and Anna Galli (D) \\ Dipartimento di Scienza dei Materiali, Università degli Studi di Milano Bicocca, Via Cozzi 55, 20125 Milano, Italy; \\ anna.galli@unimib.it \\ * Correspondence: m.martini@unimib.it; Tel.: +39-02-64485166
}

Citation: Martini, M.; Galli, A.

Thermoluminescence Analysis of the Clay Core of Bronze Statues: A Re-Appraisal of the Case Studies of Lupa Capitolina and Other Masterpieces in Rome. Appl. Sci. 2021, 11, 7820. https://doi.org/10.3390/ app11177820

Academic Editor: Dimitris Mossialos

Received: 31 July 2021

Accepted: 24 August 2021

Published: 25 August 2021

Publisher's Note: MDPI stays neutral with regard to jurisdictional claims in published maps and institutional affiliations.

Copyright: (c) 2021 by the authors. Licensee MDPI, Basel, Switzerland. This article is an open access article distributed under the terms and conditions of the Creative Commons Attribution (CC BY) license (https:/ / creativecommons.org/licenses/by/ $4.0 /)$.

\begin{abstract}
In this work, we present some new results in applying thermoluminescence (TL) dating to the clay core of bronze statues. This is very important, due to the impossibility of directly dating a metal. Very few cases of indirect dating of clay cores by TL are reported in the literature. We re-considered three cases of dating of clay core from important bronzes in Rome. The parameters to be considered were not easy to calculate in the case of the Lupa Capitolina. However, its traditionally reported Etruscan origin is definitely ruled out, even if the accuracy in the dating is too low to precisely propose a date of the casting. The comparison with radiocarbon results shows good agreement for a Medieval dating. Two other bronze statues were analysed in order to date their casting by TL; a horse from Musei Capitolini resulted to have been cast in the Greek classical period, excluding its casting in the Rome imperial period. A third study shows that, in particularly favourable situations, TL dating of clay core can give rather precise results. This is the case where in the clay core are present materials that behave like good dosimeters, as generally happens in dating ceramics. Furthermore, the possibility of measuring all the parameters influencing the calculation of the dose rate is essential; both the external radiation sources and the radiation reduction by the water content must be taken into account. This was the case of Saint Peter in the Vatican that turned out to be a cast from the beginning of the XIV century.
\end{abstract}

Keywords: thermoluminescence; dating; clay-core; bronze statue

\section{Introduction}

The use of delayed luminescence in dating ceramic objects dates back to the Sixties of the past century. It is based on dosimetric principles; in practice, the first type of delayed luminescence, thermoluminescence (TL), uses the light emitted obtained by heating a sample as a measurement of the previously absorbed radiation dose by the sample under study, since its last heating to high temperature. In the next section, a few details are given to better describe the phenomenon.

The linear relationship between emitted light and accumulated dose is fundamental in making TL a very good dosimetric technique. It is currently used to measure the exposure to radiation of professionals working in radiation fields, such as radiologists. Of course, in these cases the materials used are tailored to present an intense emission as a consequence to radiation exposure, well suited to be detected, as it is detailed in the following.

On the contrary, in the application of TL to dating, the material to be used cannot be chosen. In many ceramics and bricks, quartz is contained in relatively large amounts and acts as a good natural dosimeter [1]. Other minerals, such as feldspars, could be good dosimeters, even if some problems are often present, such as the lack of stability of the source of TL signal in time, the so-called "anomalous fading" [2].

In order to date a ceramic by TL, the total absorbed dose since the last heating that generally corresponds to its making in a kiln can be determined by comparing the light 
emitted due to the exposure to the natural radiation environment in the centuries to artificial irradiations in laboratory. It must be noted that different radiation doses can be accumulated in different samples of the same age, depending on the dose rate, that is, the higher the dose rate, the more intense the natural irradiation. Therefore, the intensity of the mentioned natural radiation environment must be measured. This can generally be achieved by determining the amount of radioactivity of the sample itself and of the surrounding environment. These measurements and the connected experimental troubles are briefly described in the next sections.

In the last decades, many applications of TL dating have demonstrated their feasibility in determining with acceptable precision the sequence in an archaeological stratigraphy or in determining the various phases of construction, modification and restoration in a historical building.

The basic idea of dating by TL can be applied, in principle, to the material remaining in the interior of a bronze statue after its casting, the so-called clay core. In favourable cases, this material behaves like a ceramic and the procedures used for dating ceramics can be also applied to clay cores. This is extremely important, considering that, with very few exceptions that are not treated here, metal objects cannot be dated by absolute techniques.

In this work, the application of TL dating to clay cores is introduced and the specific difficulties deriving from the characteristics of this material, together with the complex determination of the radiation environment, are commented on. Very few cases of application of TL to the dating of clay cores are present in the literature $[3,4]$, mainly due to the many sources of uncertainty mentioned above and to the difficulties in correctly managing the experimental data. The first application of TL techniques to clay cores dates back to 1974, when D.W. Zimmermann [3] succeeded in testing the authenticity of core materials from a Bronze Horse of the New York Metropolitan Museum of Art. Other examples of TL applied to clay core are reported, still in the field of authenticity test [5].

In the last decades a few interesting studies of TL dating were carried out in our laboratory (Lupa Capitolina, the horse bronze statue from Musei Capitolini and the Saint Peter statue); they are re-considered in this work aiming at obtaining more accurate results by applying new statistical approaches.

The cases of clay-core dating by TL presented here regard important bronze statues in Rome, including the Lupa Capitolina. Sometimes, a rather precise age determination was reached; in some others, it was possible to solve the doubt between two different proposed ages. In this paper, a few results already preliminarily presented are discussed, together with new data and some statistical new calculations aimed at better understanding the dates by TL, when compared with dating results obtained by other techniques.

\section{Luminescence Dosimetry}

As already mentioned, it is possible to record the exposure to a radiation field by the use of delayed luminescence. Two main types of this kind of feature are currently exploited, thermally- and optically-stimulated luminescence, TSL and OSL, respectively.

Thermoluminescence, or thermally-stimulated luminescence (TL or TSL) is a particular way in which a material emits light, i.e., a luminescence phenomenon [6]. It is a long-lived phosphorescence, in that the light emission is retarded due to the presence of metastable levels, which act as charge "traps", where generally these charges are electrons, of the material. In simple terms, the absorption of energy, mainly from ionising radiation, causes the excitation of electrons in the material, some of which are trapped at the previously mentioned metastable levels, the traps. A subsequent heating of the material, de-trapping the electrons, allows the recombination at luminescence centres, with a consequent light emission, the TL. Similarly, OSL is based on the light emission under optical stimulation; of course, the stimulating light must be different, i.e., with a different wavelength, from the detected emitted light.

In this paper, we focus on TL, but most of the presented procedures are very similar in TL and OSL studies. It must be noted, however, that, in case of TL, the measured radiation 
amount refers to the period since the last high temperature heating, while in OSL the measured radiation refers to the period since the last light exposure. It can then be applied to materials that have remained in the dark since then, such as sediments. More details on OSL fundamentals and applications can be found elsewhere [6].

When it was discovered that the amount of TL was somehow proportional to the previously absorbed radiation dose, the possibility of using TL as a dosimetric technique was manifested. It was only in 1960 that the practical procedure for quantitative TL measurement was exploited and many TL materials have since then been studied and developed to be used in radiation dosimetry. The result of a TL measurement is the socalled "glow curve" (see Figure 1), which reports the intensity of the emitted light as a function of the temperature; the presence of a peak is related to a previous charge trapping at a certain site. It is strongly dependent on the heating rate, as the position of a peak moves toward higher temperature with increased heating rate.

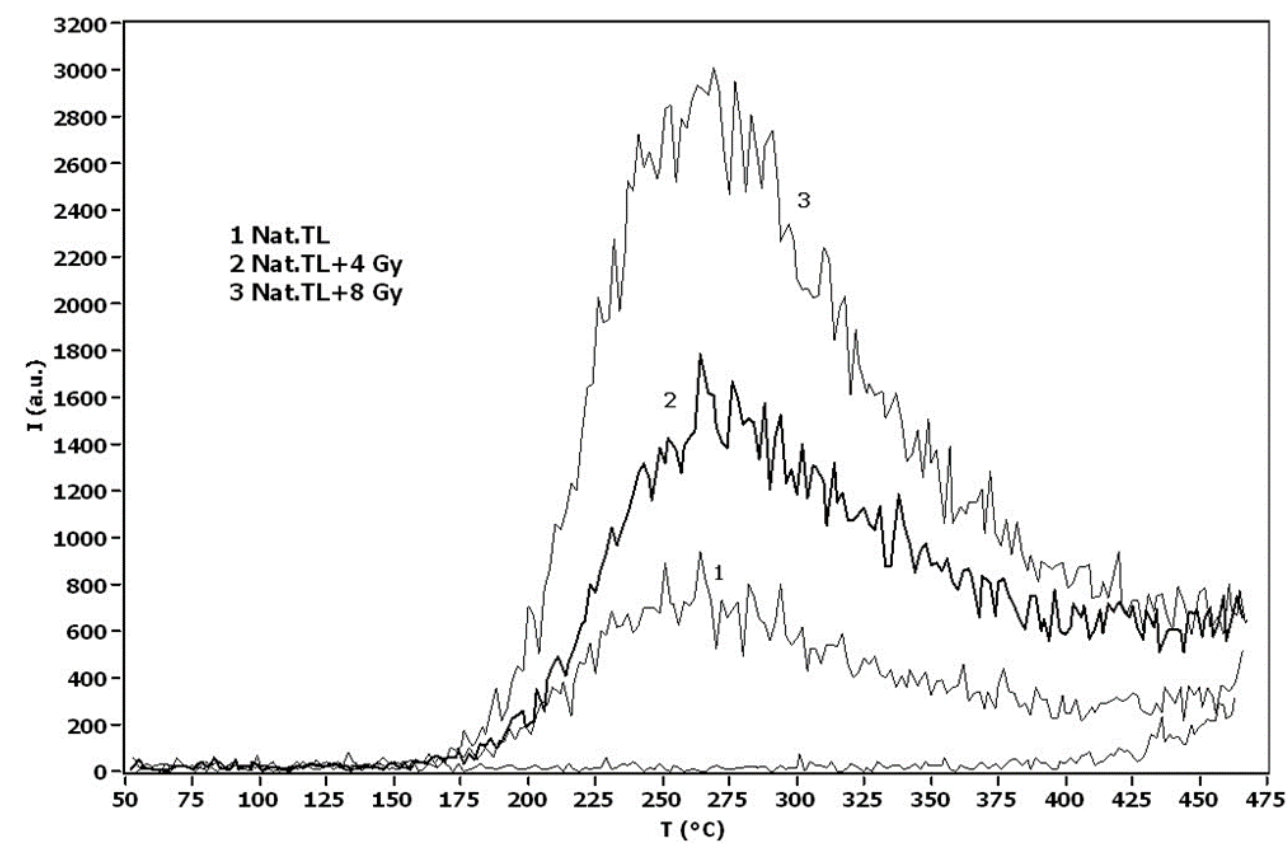

Figure 1. TL glow-curves, example of a clay core extracted from the Lupa Capitolina.

The main characteristics needed by a TL material are: (i) the linearity between emitted TL and absorbed dose, or at least a good knowledge of the relationship between TL and absorbed dose, (ii) the presence of peaks in the glow curve at suitable temperature and (iii) the emission wavelength in the visible or near UV region.

\section{Thermoluminescence Dating}

A particular kind of TL dosimetry is TL dating that was developed in the 1960s. It rapidly became one of the most diffused dating techniques, somehow complementary to radiocarbon dating; TL is used to date inorganic materials, mainly ceramics, while radiocarbon can be applied to organic materials. Luminescence dating has also turned out to be useful in different fields apart from archaeology and historical architecture, in particular in accident dosimetry, while OSL is widely exploited in sediment dating.

In both TL and OSL dating, the materials whose luminescence can be measured are, of course, the minerals naturally present in the objects to be dated; quartz and feldspars are the most diffused minerals contained in ceramics. Looking at TL, their properties are generally good enough, even if the emitted TL is not always proportional to the absorbed dose, due to possible variations in the TL efficiency that must be checked. Besides, in feldspars, the already mentioned phenomenon of "anomalous fading" is often present; it consists in the de-trapping of electrons not due to thermal stimulation and it results in the 
erasure of part of the TL signal before its measurements. The ways of dealing with such complex behaviours, in order to correctly determine the absorbed dose, have been deeply treated [2].

Looking at the natural radiation field, it comes from both outside, the cosmic rays, and from inside the Earth, the natural radionuclides. These latter are mainly Potassium 40, Uranium 238 and Thorium 232, the last two together with their decay products that are also radioactive, so that they constitute two radioactive families, originating a number of alpha, beta and gamma emissions.

Due to its decay, the intensity of a radioactive substance, its "activity", measured in decays per second, varies with time. In the case of natural radionuclides, being their decay time in the order of 109 years, the activity can be considered constant for relatively "short" times, as they are when treating historic periods (less than 104 years). The interaction of ionising radiation with matter results in a transfer of energy that depends on the type of emitted particles and on the absorbing medium.

The possibility of dating pottery and other materials using TL is based on the same principles on which dosimetry is ground. In fact, the quartz and feldspars crystals usually present in clays act as TL dosimeters; when the clay is heated, to make a pottery or a brick, all the traps are emptied. From that moment, a new filling of the traps starts due to the irradiation by the natural radioactive elements contained in the pottery and in the surrounding environment.

To summarize these mechanisms, there is a fundamental TL dating equation:

$$
\text { Age }=\frac{\text { Palaeodose }}{\text { Dose }- \text { rate }}
$$

The palaeodose is the total absorbed dose since the last heating at high temperature that generally coincides with the making of the pottery (it can sometimes be due to accidental heating, such as in the case of a fire). It is calculated from a comparison between the "natural" TL produced by the irradiation by the natural radioactivity and the "artificial" TL due to laboratory irradiation with artificial sources, whose intensity is known (see Figure 1).

The dose rate is due to internal radioactive impurities in the object to be dated and external impurities in the surrounding environment, e.g., the burial soil in an archaeological excavation, or the building itself when dating bricks. The internal dose is given by alpha and beta radiation, while the external dose comes from the environmental gamma radiation and, to a lesser extent, to cosmic rays; more details can be found in the specialized literature on the topic [2]. In most cases, the internal radioactivity gives $70-80 \%$ of the total dose rate. This constitutes a sizable advantage, because uncertainties in the past environment give limited errors in the calculation of the age. As we explain here, this is not always true when dating clay cores, where it can be a relevant source of uncertainty.

With potteries of Roman-Greek periods, we are dealing with a palaeodose ranging from a few grays to a few tens of grays, where the gray (Gy) is the unit for absorbed dose, i.e., energy per unit mass, and corresponds to 1 Joule per kilogram of absorbing material. The dose rate is usually within the range from 1 milligray per year (mGy/a) to 10 milligrays per year (mGy/a).

As regards the evaluation of the dose rate, due to the very low levels of natural radioactivity, very sensitive techniques have been developed. It must also be taken into account that the effective dose rate is dependent on the water contents of the sample and the soil; this is because one can calculate the exposure to radiation when the radioactive contents of the sample and the environment are known. However, the water present in the pores of the sample absorbs part of the energy emitted by the radionuclides; this means that the dose effectively absorbed by the sample is reduced due to the presence of water. As a result, it is necessary to know, with the highest possible accuracy, the amount of water present in the sample in the centuries, which cannot always be achieved. Typically, there may have been changes in the position of the sample to be dated and in the water 
content in the past. This source of uncertainty can be a limiting factor when dealing with clay-core dating.

\section{TL Dating of Clay Cores: Materials and Method}

In the preceding section, the main steps of TL dating and the sources of uncertainty are shortly summarized. It is important to consider how these factors can limit the application of TL dating to clay cores. The precise evaluation of both palaeodose and dose rate requires considering the various factors affecting the calculations.

As regards the measurement of the palaeodose, it must be remembered that the composition of the various clay cores can widely vary from case to case. In fact, the materials that remain in a bronze statue after its casting by the lost-wax technique can be composed not only by clay, but also by many materials of various origin; they were added to allow the attenuation of the huge variations in volume, as an effect of high temperature changes during the casting and after it. Not only inorganic materials, such as clay, but also organic materials, for example, straw, were put inside the object to be cast, in order to attenuate expansion and contraction deriving from the temperature variations. The effects on the TL properties of the materials that can possibly be extracted from the inside of a bronze statue can be important; the presence of organic material is generally a source of the so-called "spurious TL", that is, a light emission independent of the absorbed dose. This phenomenon can also be present in potteries. It is generally attenuated by carrying out the measurements in an inert atmosphere, typically in nitrogen. This is also conducted with clay cores, but the low intensity of the "good" TL signal, as compared with the spurious $\mathrm{TL}$, can constitute a limiting factor in dating clay cores by TL.

A further important point in dating clay cores by TL, especially meaningful with statues found in archaeological excavations, is the presence of materials that were not submitted to the original casting, typically some soil remains that obviously were not submitted to high temperature heating.

In the cases presented in this work, the material extracted from the clay core was submitted to grain selection in order to apply the "fine grain" technique [2]. This implies that the contribution of the natural alpha dose had to be taken into account; alpha irradiation by an ${ }^{241} \mathrm{Am}$ source was carried out in laboratory in order to determine the efficiency of alpha irradiation with respect to the gamma and beta ones [2].

As concerns the measurement of the dose rate, as we explore in some of the following case studies, it would be very important to know, with a good accuracy, the history of the statue to be dated, in order to estimate the external contribution to the dose rate, that is known not to depend on the clay core, but rather on the environmental radiation field.

A second factor affecting the dose rate is the knowledge of the water content of the clay core in the past, whose effect is the attenuation of the dose rate, hence the increase in the date obtained for the measured clay core, as calculated from the radioactivity content of the clay core itself and its environment.

In the cases presented in this work, the radioactivity content of the clay cores was calculated by alpha counting using $\mathrm{ZnS}(\mathrm{Ag})$ detectors [2] and through the measurement of the total Potassium content by flame photometry; the contribution due to the radioactive

${ }^{40} \mathrm{~K}$ content is easily calculated on the base of its well-known isotopic concentration [2]. The environmental dose rate, as it is detailed in the following, could not be measured due to the lack of information on the external irradiation in the centuries and only speculations could be proposed.

We summarise the specific application of TL dating to clay cores and its difference when compared with the application to potteries and to bricks as follows:

- the materials that constitute the clay core can contain organic materials and spurious TL is expected, also considering a weak signal often found in clay-core materials;

- the clay core can be contaminated by soil particles, not erased by the casting and, consequently, the measured absorbed dose can be overestimated; 
- an accurate calculation of the external dose rate sometimes can hardly be determined, due to the ignorance of the history of the object under study, as opposed to an archaeological excavation, or a brick from a building that has been exposed to the same dose rate for centuries.

Similar speculations are valid for the role of the absorbed water, whose effect is the increase in the calculated date, when known. As discussed above, it is generally possible to estimate, sometimes with good accuracy, the water content for an object coming from an archaeological excavation and, even better, from a building. Very difficult is the estimation of the water content inside a bronze statue in the centuries.

\section{TL Dating of Clay Cores: A Reappraisal of Some Case Studies}

As mentioned in the introduction, few TL studies of the clay cores of bronze statues have been devoted to determining their authenticity, rather than calculating an absolute dating. Further attempts devoted to dating soon enlightened a series of difficulties, complications and limiting factors, as mentioned above. However, in some favourable or particularly meaningful cases, very important results have been achieved.

We report here three case studies whose results have been discussed in the past and have been recently re-considered, obtaining information more relevant than that from past-published data. They regard (i) the famous Lupa Capitolina, that has been always considered as the symbol of the Rome itself, (ii) a bronze horse in natural dimensions, exposed in the Musei Capitolini, like the Lupa, that could be a Greek original or a Roman copy, such as many bronze statues in Rome, and iii) the statue of San Peter in the Vatican, whose chronological assignment has been long under discussion.

\subsection{Lupa Capitolina: TL Study of the Clay Core}

During the extensive restorations underwent in the period from 1997 to 2000, several samples of clay core were taken from the Lupa Capitolina and submitted to TL studies with the aim of dating its casting [4]. This goal could not be directly reached, due to the complex environmental irradiation history. Nevertheless, it was possible to demonstrate that the statue was cast with maximum of probability between the VIII and XIV century $\mathrm{AD}$, so the traditionally reported Etruscan origin of the statue was ruled out. Recently, Calcagnile et al. [7] had the opportunity to apply AMS radiocarbon dating on, overall, 34 organic residues sampled form the casting cores within the statue.

In view of these results, we crosschecked the TL dates with the radiocarbon ones. We considered the combination of the thirty-four 14C ages (see Figure 6 in reference [7]).

For what concerns the TL dating, it was possible to have access to the interior of the statue for clay core sampling, by hand, by dry laser ablation and with an endoscope specially adapted [4]. The cores had a homogeneous calcareous marl-like composition, rich in silicate and carbonate components, to which abundant inorganic temper was added [8]. For the experimental details, see Martini and Sibilia [4].

By summarising the achieved results, the TL emission of the samples was characterised by a good sensitivity to radiation, but sometimes by scarce reproducibility; therefore, errors in palaeodose were quite high $( \pm 10 \%)$. As for the dose rate evaluation, even if the concentrations of uranium and thorium were quite homogeneous and the potassium oxide contents were more scattered (standard deviation, $26 \%$ of the mean value). The possibility of enrichment of potassium due to percolation of water could perhaps account for this phenomenon.

Finally, speculations on the mean water content during time were performed; the saturation water of the samples was evaluated, but this measured value was used with great caution, giving account for possible significant variations. Moreover, as we already mentioned in the previous section, the assessment of the ambient contribution to the annual dose rate is problematic and this case study was no exception; the measured value refers only to the conservation in the museum and does not take into account any correction for the attenuation due to the metal layer. 
So, as expected, TL dating results were strongly dependent on the attenuation of the external dose by the bronze thickness and on the water content. In such a situation, it was therefore attempted a probabilistic approach to the dating problem by focusing the attention on the five solid samples taken from the inner part of the Lupa (D1343/LL4, D1278/LS, D1342/M1, D1344/M2 and D1226/V1, see Figure 2). For these samples, dust contamination could be excluded and humidity conditions and external irradiation were reasonably more constant during time.

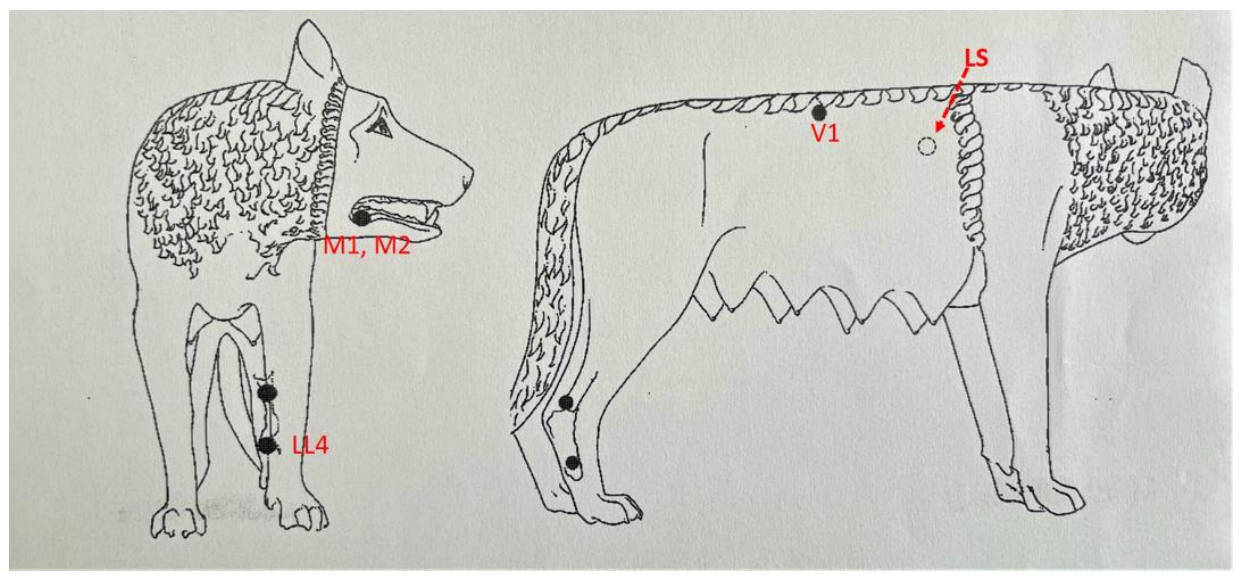

Figure 2. Lupa Capitolina, sampling position of the clay core samples.

In Figure 3, the dating results are plotted as a function of the water content, excluding the extreme values relative to dry and saturated conditions, which were very unlikely. The results shown suggest that the casting could not have occurred before the VIII century nor after the XIV century.

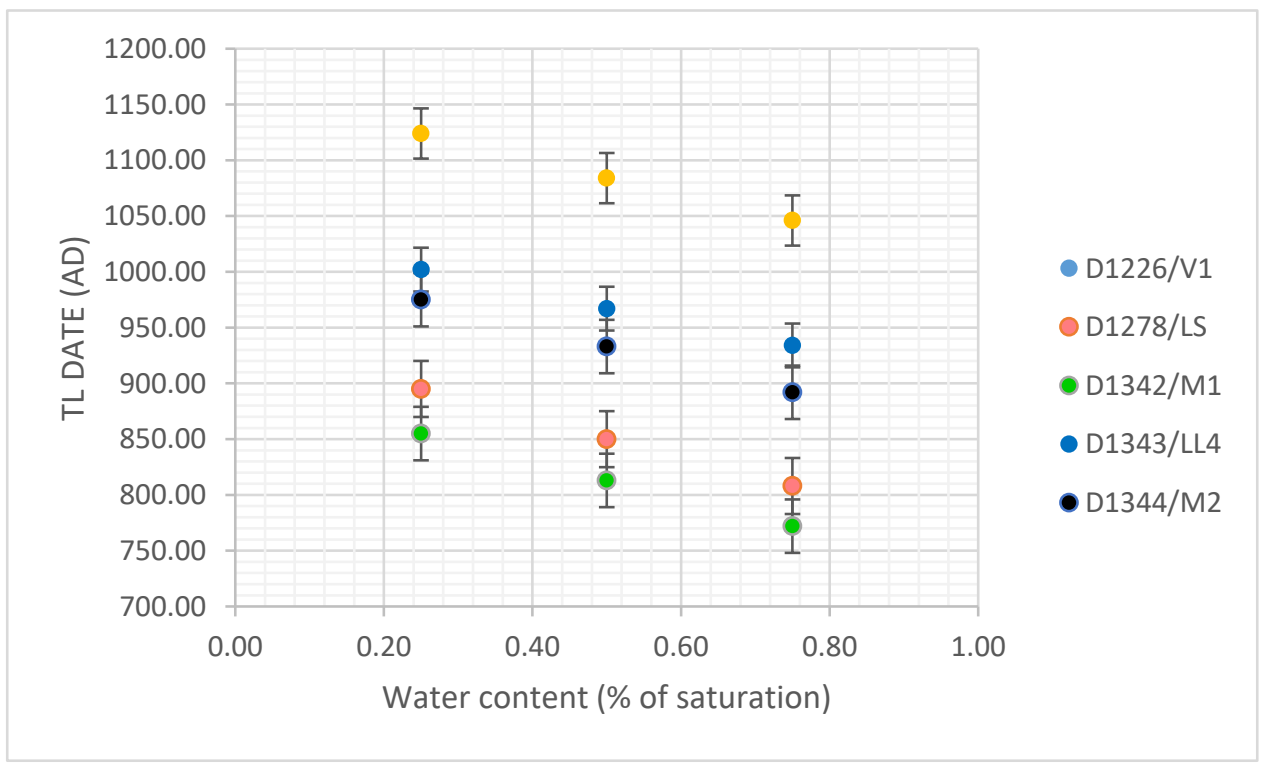

Figure 3. Possible dates for casting (water content, $25-75 \%$ of saturation; effective external dose rate, $1.5 \pm 0.5 \mathrm{mGy} / \mathrm{a})$.

Putting all the $14 \mathrm{C}$ and TL data together (see Figure 4), it appears that, regardless of the chosen percentage of saturation of water content, the TL date of three out of the five samples agree within two standard deviations with the radiocarbon date (namely D1343/LL4, D1344/M2 and D1226/V1). 


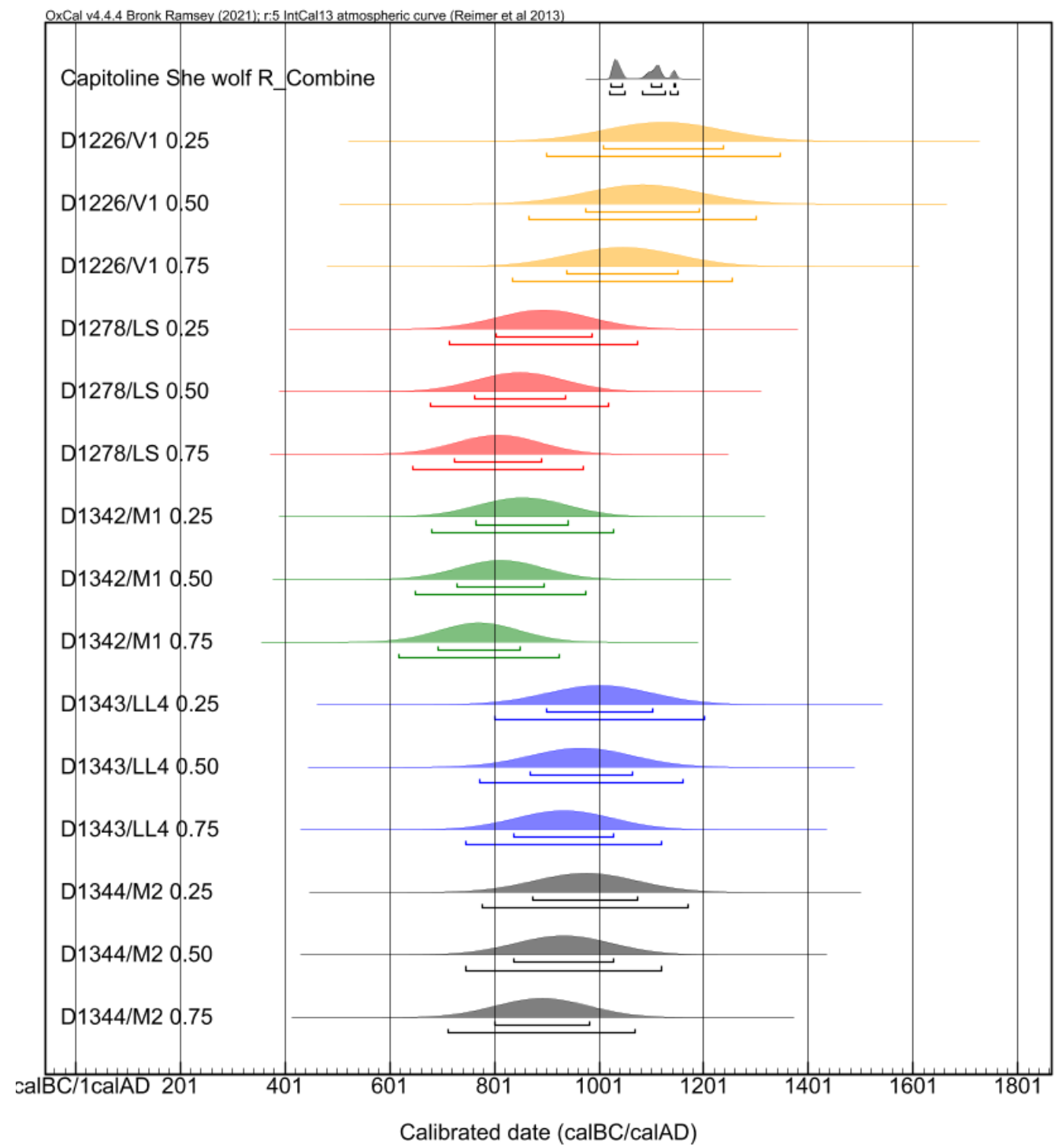

Figure 4. Comparison between the possible TL dates (water content, 25, 50 and 75\% of saturation) and the combined radiocarbon date ([7]).

The two samples (D1278/LS and D1342/M1) in disagreement with the combined radiocarbon date are little dependent on the water content. These results seem to put in evidence that if the clay cores are sampled from volumes that have reasonably uniform humidity conditions and external irradiation over time, the estimation of the water content inside the bronze little affects the obtained age.

At this point, we could choose $50 \%$ as a value for water content and we applied the R_Combine function of OxCal 4.4.4 [9] to the two sub-set of samples (D1343/LL4, D1344/M2, D1226/V1 and D1278/LS, D1342/M1). The results obtained from the first sub-set (see Figure 5) show an agreement with a confidence level of $95.4 \%$ with the radiocarbon age. 


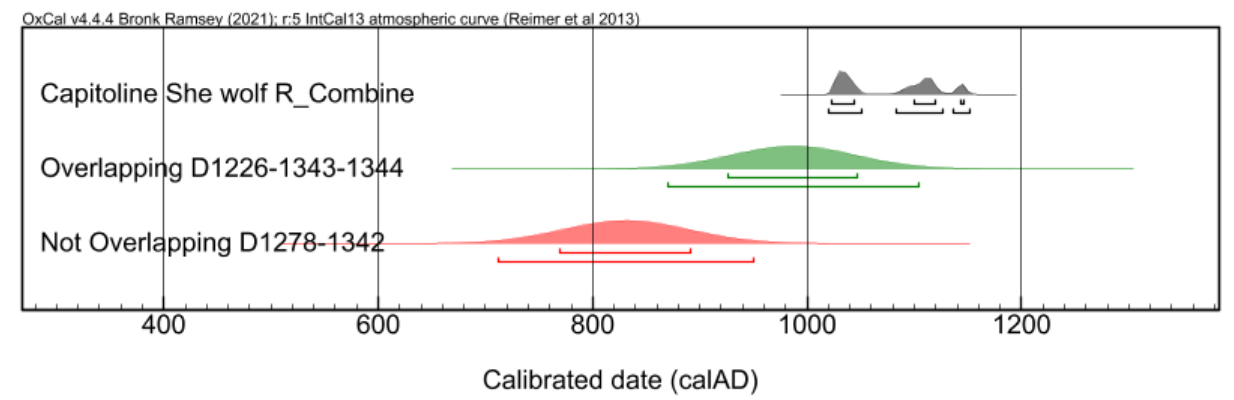

Figure 5. Comparison between the combined radiocarbon date ([7]) and the combination of the two sub-sets of TL dates.

\subsection{The Horse Bronze Statue from Musei Capitolini, Rome}

In 1894, a number of bronze objects were found in an old cellar in Rome, some of them of great artistic interest. Among them, a beautiful statue of a horse, heavily damaged, was transferred to Musei Capitolini and adequately restored. The statue, see Figure 6, is of natural size and has been exhibited in the Musei since then.

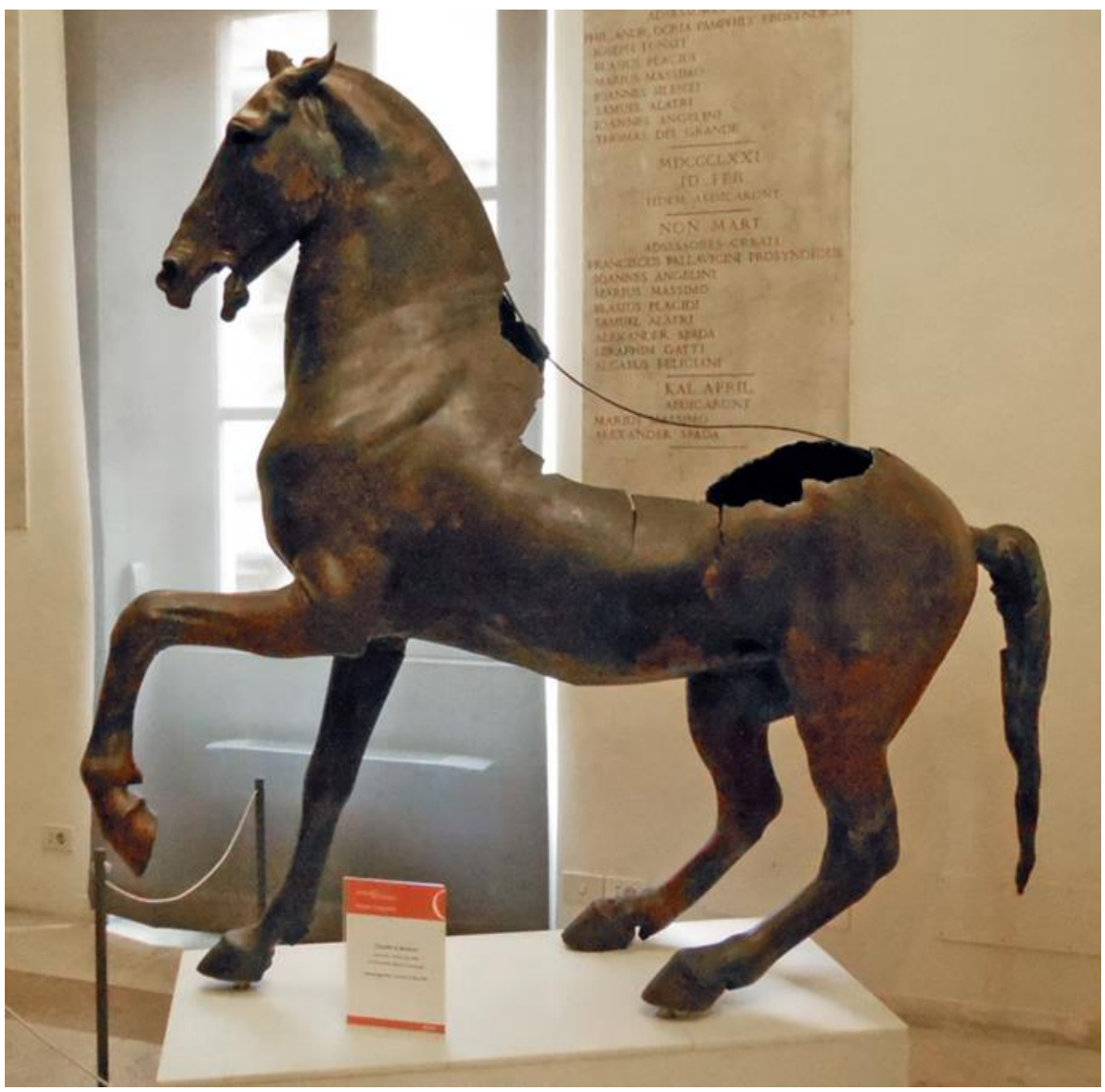

Figure 6. Sculpture, bronze horse, (Capitoline Museum, Rome, Italy). Ph credits Di MM -Opera propria, CC BY-SA 3.0, https: / / commons.wikimedia.org/w/index.php?curid=22426880, accessed on 31 July 2021.

More than thirty years ago, the statue was submitted to a program of restoration and studies. By the study of the internal clay core, we tried to determine the date of the casting. The problems we faced are presented in Section 4; the expected accuracy could not be very high, either for the material constituent of the clay core, which cannot always be considered a ceramic, or for the difficulties in precisely determining the radiation exposure, due to the uncertainties in the external dose and in the water content. The case of the clay core 
from the horse statue was rather favourable, at least as regards the type of the constituent material, which did not present any spurious TL, and the calculation of the total absorbed palaeodose could give a rather low uncertainty and similar results among the three samples taken from the interior of the statue. The palaeodose, as measured applying the "fine-grain technique" resulted as $\mathrm{D}=13.2 \pm 0.6 \mathrm{~Gy}$ and was published in a review book [10]. The dating of the statue could not be determined due to the poor information about the dose rate, but a clear indication of a Greek origin was reached, due to the rather elevated value of palaeodose, whatever the dose rate might be, within reasonable values. In the present re-calculation, new information was added and a more reliable assignment of the casting to the Greek period was reached.

We start from the data already obtained in the first measurements, i.e., the internal dose rate, which turned out to be $3.4 \pm 0.3 \mathrm{mGy} / \mathrm{a}$. Furthermore, the reported value must be considered as the maximum value of internal dose rate, because any water content would reduce this value. The measurement of the external dose rate, of course, is one of the main sources of uncertainty, together with the water content in the past, as discussed in Section 4. To try to obtain an acceptable value of external dose rate, a dosimetric measurement of the gamma dose rate in the cellar where the statue was found in 1984 was necessary. This value was $4.1 \pm 0.3 \mathrm{mGy} / \mathrm{a}$, once more without taking into account the role of water content [4].

To summarise the external dose rate, the statue was exposed to three different dose rates: the first for an unknown period, $t_{1}$, until it was abandoned in the cellar where it was found, a second for the period $t_{2}$ in the cellar and a known third period, $t_{3}$, in Musei Capitolini.

Therefore, having evaluated the dose rates related to the three periods and the palaeodose, it was possible to calculate the statue age by solving a simple parametric equation:

$$
\left\{\begin{array}{c}
\mathrm{T}=\mathrm{t}_{1}+\mathrm{t}_{2}+\mathrm{t}_{3}=\frac{\mathrm{D}_{1}}{\mathrm{~d}_{1}}+\frac{\mathrm{D}_{2}}{\mathrm{~d}_{2}}+\mathrm{t}_{3} \\
\mathrm{D}=\mathrm{D}_{1}+\mathrm{D}_{2}+\mathrm{D}_{3}
\end{array}\right.
$$

where $T$ is the age of statue (the dose rates $d_{1}, d_{2}$ and the period $t_{3}$ were evaluated) and D is the palaeodose $\left(\mathrm{D}_{3}\right.$ was calculated).

By solving (2), it is possible to obtain the age of casting of the statue as a function of the unknown period $t_{1}$ :

$$
\mathrm{T}=\mathrm{mt}_{1}+\mathrm{q}
$$

where

$$
\left\{\begin{array}{c}
\mathrm{m}=1-\frac{\mathrm{d}_{1}}{\mathrm{~d}_{2}} \\
\mathrm{q}=\frac{\mathrm{D}-\mathrm{D}_{3}}{\mathrm{~d}_{2}}+\mathrm{t}_{3}
\end{array}\right.
$$

Figure 7 shows the straight lines obtained in the complete absence of water in the clay cores and with water concentrations varying from $2 \%$ to $10 \%$.

Larger percentages are considered unlikely due to the compactness of the material. The intercept of the lines at $t_{1}=0$ provides the age of the horse in the various humidity hypotheses and is the minimum possible in the various cases. The straight line corresponding to $0 \%$ water content represents an unrealistic situation but identifies the lower limit of $\mathrm{T}$ for the different values of $t_{1}$. Reasonable values of water content (5-10\%) and outdoor periods $\left(100<t_{1}<300\right.$ years) lead to the more likely age between about 2300 and 2400 years and, so, assign the casting of the bronze horse to the classical Greek era. 


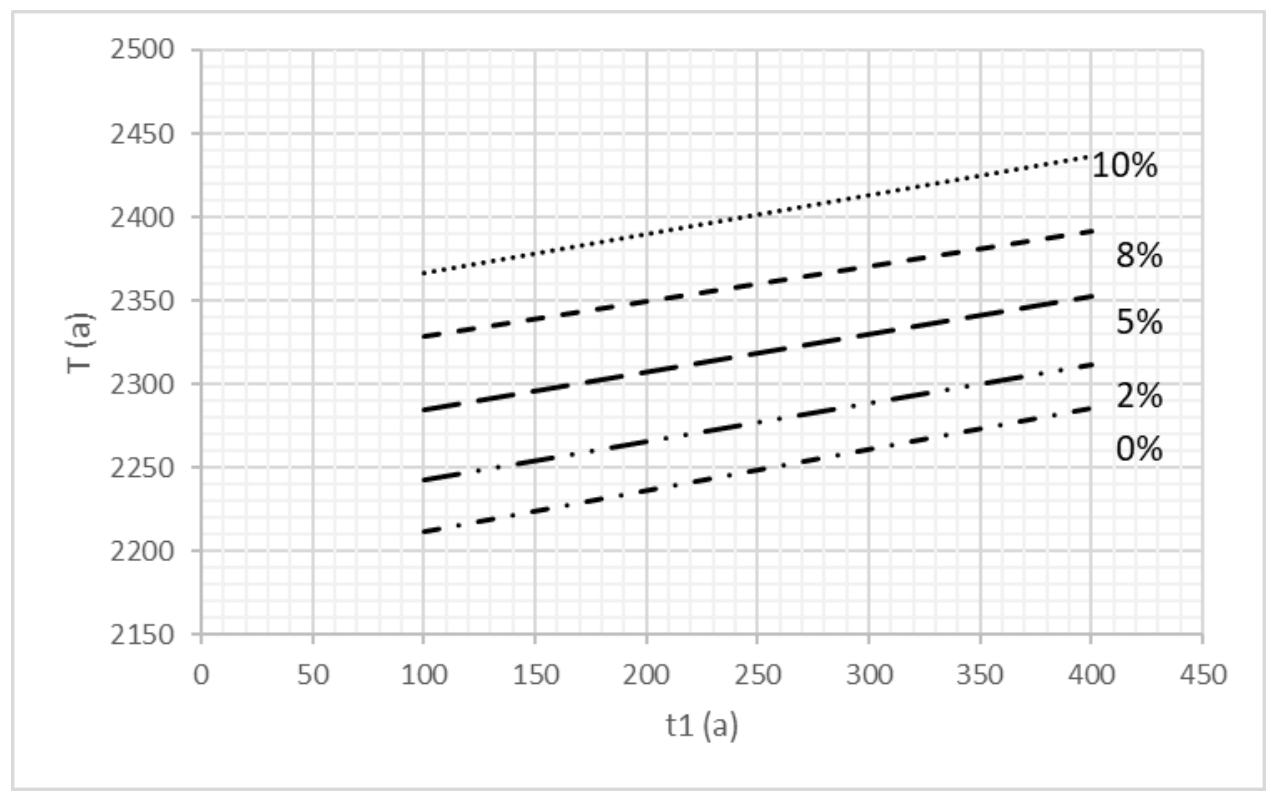

Figure 7. Time elapsed since the casting vs. the period of the outdoor location. Different concentrations of water in the burial environment were considered.

\subsection{The Statue of Saint Peter in the Vatican}

A case in which a clay core behaves almost like a ceramic was found in the analysis of the statue of Saint Peter in the Vatican Basilica in Rome (see Figure 8).

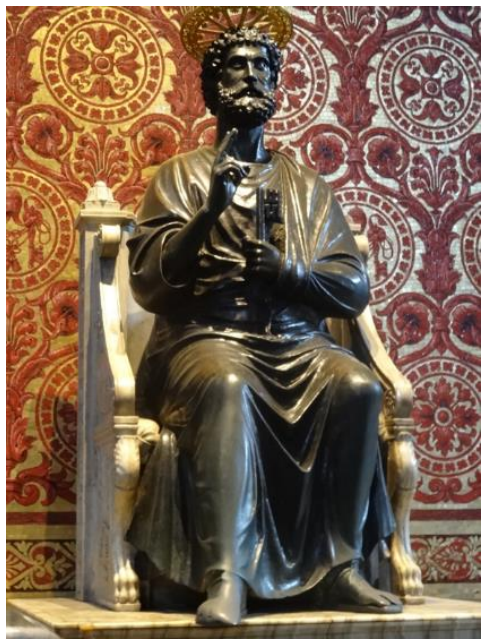

Figure 8. Bronze Statue of Saint Peter (Arnolfo Di Cambio, St. Peter's Basilica, Rome, Italy). Ph credits Jordiferrer, CC BY-SA 4.0 <https:/ / creativecommons.org/licenses/by-sa/4.0, accessed on 31 July 2021>, via Wikimedia Commons.

The clay core found inside the statue was indeed mostly constituted by clay, which gave a very good dosimetric response [11]. All the three measured samples gave repeatable luminescence intensity and a linear response to the artificial irradiation by the radioactive sources in laboratory. It was then possible to obtain values of the palaeodose in a very narrow Gaussian distribution; the obtained value was $2.7 \pm 0.2 \mathrm{~Gy}$. The homogeneity of the material inside the statue allowed a precise determination of the radioactivity content of the clay core; then, the internal dose rate turned out to be $3.3 \pm 0.1 \mathrm{mGy} / \mathrm{a}$. The compactness of the clay core allowed to reduce to a very low level the effect of the water content; it must be highlighted that it is almost certain that the statue was put where it is now since its making. As a further consequence, the external dose could be evaluated, taking in due account 
the attenuation of the bronze itself. All that considered, the annual dose rate resulted to be $3.9 \pm 0.2 \mathrm{mGy} / \mathrm{a}$, whose value put in the age equation gave $680 \pm 60$ years, hence determining a date for the casting of the statue at the beginning of the XIV century. This is in good agreement with the proposal of scholars who attribute it to Arnolfo di Cambio. The dating of this statue is a particularly favourable case of dating clay core taken from the inside of a bronze statue. This is evidently due to the good quality of the clay core itself, in the sense that it was a material very similar to a ceramic, and to the utmost importance of the possibility of determining all the variables contributing to the radiation dose rate, that, in the case of a statue very likely to have been always in the same environment, can all be determined with good precision.

\section{Conclusions}

Dating clay cores of bronze statues by TL is the only possibility of reaching a chronological determination for the casting of the statues, due to the impossibility of directly dating a metal. Here, it is shown how complex is the application of TL to clay cores. Nonetheless, important results can be achieved by accurate analysis of the experimental data and by a correct statistical management of these data.

The sources of uncertainties can highly reduce the dating precision, either due to the materials, because the clay core is not a ceramic, and due to the difficulties in the calculation of the dose rate. The internal dose rate can be strongly affected by an unknown water content that reduces the dose rate in the centuries, while the external dose rate can be assessed sometimes with large uncertainty, due to the difficult reconstruction of the life of the statue in time. We re-considered three cases of clay-core dating from important bronzes in Rome. The traditionally reported Etruscan origin of Lupa Capitolina is definitely ruled out, even if the precision in the dating is too low to allow precise proposals for the date of casting. The statistical comparison with radiocarbon results shows good agreement for a Medieval dating.

A horse from Musei Capitolini is assigned to a casting in the Greek period, rather than a Roman casting.

A third study relative to the statue of Saint Peter in the Vatican shows that, in particularly favourable situations, the dating of clay cores can be similar to the dating of ceramics. It is necessary to find materials in the clay core behaving like good dosimeters and the possibility of measuring all the parameters influencing the calculation of the dose rate is essential, such as in the case of the Saint Peter statue, which has very likely always been kept in the same radiation field.

Simple Summary: The basic idea of dating by TL can be applied, in principle, to the material remaining in the interior of a bronze statue after its casting, the so-called clay core. In favourable cases, this material behaves like a ceramic and the procedures used for dating ceramics can be also applied to clay cores. This is extremely important, considering that, with very few exceptions that are not treated in this paper, metal objects cannot be dated by absolute techniques. In this work, the application of TL dating to clay cores is introduced and the specific difficulties deriving from the characteristics of this material, together with the complex determination of the radiation environment, are commented on.

Author Contributions: Conceptualization, M.M.; writing-original draft preparation, M.M. and A.G.; writing-review and editing, M.M. and A.G.; supervision, M.M. All authors have read and agreed to the published version of the manuscript.

Funding: This research received no external funding.

Institutional Review Board Statement: Not applicable.

Informed Consent Statement: Not applicable.

Acknowledgments: This work was also possible thanks to all researchers that have collaborated with us during the activity of our laboratory. We would like to mention Francesco Maspero particularly, for helping us with the elaboration of data in the case study of Lupa Capitolina. 
Conflicts of Interest: The authors declare no conflict of interest.

\section{References}

1. Preusser, F.; Chithambo, M.L.; Götte, T.; Martini, M.; Ramseyer, K.; Sendezera, E.J.; Susino, G.J.; Wintle, A.G. Quartz as a natural luminescence dosimeter. Earth-Sci. Rev. 2009, 97, 184-214. [CrossRef]

2. Aitken, M.J. Thermoluminescence Dating; Academic Press: London, UK, 1984; pp. 331-351.

3. Zimmermann, D.W.; Yuhas, M.P.; Meyers, P. Thermoluminescence authenticity measurements on core material from the Bronze Horse of the Metropolitan Museum of Art. Archaeometry 1974, 16, 19-30. [CrossRef]

4. Martini, M.; Sibilia, E. Thermoluminescence Study of the Clay Core of the Lupa Capitolina. BOREAS 2009, 32, 187-194.

5. Bassett, J. Thermoluminescence dating for European sculpture: A consumer's guide. Objects Spec. Group Postprints 2007, 14, 32-46.

6. Boetter-Jensen, L.; McKeever, S.W.S.; Wintle, A.G. Optically Stimulated Luminescence Dosimetry, 1st ed.; Elsevier: Amsterdam, The Netherlands, 2003; Chapter 5; pp. 119-224.

7. Calcagnile, L.; D’Elia, M.; Maruccio, L.; Braione, E.; Celant, A.; Quarta, G. Solving an historical puzzle: Radiocarbon dating the Capitoline she wolf. Nucl. Inst. Methods Phys. Res. Sect. B 2019, 455, 209-212. [CrossRef]

8. Lombardi, G. A petrographic study of the casting core of the Lupa Capitolina bronze sculpture (Rome. Italy) and identification of its provenance. Archaeometry 2002, 44, 601-612. [CrossRef]

9. Ramsey, C.B. Research Lab for Archaeology. Available online: https://c14.arch.ox.ac.uk/oxcal.html (accessed on 2 June 2021).

10. Martini, M.; Sibilia, E.; Spinolo, G. Studio della Termoluminescenza di terra di fusione: Cavallo di bronzo dei Musei Capitolini di Roma. In Proceedings of the $2^{\circ}$ Conferenza Internazionale Sulle Prove Non Distruttive, Metodi Microanalitici e Indagini Ambientali Per lo Studio e la Conservazione Delle Opere D'arte di: Istituto Centrale per il Restauro, Perugia, Italy, 17-20 April 1988.

11. Martini, M.; Sibilia, E.; Spinolo, G.; Zelaschi, C. Indirect dating of bronze artifacts using their thermoluminescent clay cores. In Proceedings of the International Symposium "The Ceramics Heritage" of the 8th CIMTEC-World Ceramics Congress and Forum on New Materials, Florence, Italy, 28 June-2 July 1994; pp. 387-391. 